\title{
Multimodal and palliative treatment of patients with pulmonary metastases
}

\author{
Natalie Baldes ${ }^{1}$, Michael Eberlein ${ }^{2}$, Servet Bölükbas ${ }^{1}$ \\ ${ }^{1}$ Department of Thoracic Surgery, Evang. Kliniken Essen-Mitte, Essen, Germany; ${ }^{2}$ Division of Pulmonary, Critical Care and Occupational Medicine, \\ University of Iowa Hospitals and Clinics, Iowa City, USA \\ Contributions: (I) Conception and design: All authors; (II) Administrative support: N Baldes, S Bölükbas; (III) Provision of study materials or patients: \\ N Baldes, S Bölükbas; (IV) Collection and assembly of data: N Baldes, S Bölükbas; (V) Data analysis and interpretation: N Baldes, S Bölükbas; (VI) \\ Manuscript writing: All authors; (VII) Final approval of manuscript: All authors. \\ Correspondence to: Servet Bölükbas, MD, PhD, FETCS, FCCP. Department of Thoracic Surgery, Kliniken Essen-Mitte, Henricistrasse 92 , 45136 \\ Essen, Germany. Email: dr.bolukbas@gmx.de.
}

\begin{abstract}
Pulmonary metastasectomy has become an important part of the multimodality treatment. Surgical practice is based on observational studies published during the last decades, since no randomized clinical trials exist on the topic. However, the overall survival can be improved after pulmonary metastasectomy in carefully selected patients. The objective of resection of pulmonary metastases is to remove all tumor while preserving as much normal pulmonary parenchyma as possible and reduce invasiveness. Contrary, nonsurgical local treatment options for pulmonary metastases include thermal ablation techniques and stereotactic ablative body radiation. Thermal ablation techniques include microwave, cryotherapy and radiofrequency ablation. The present review article gives an overview on the topic and should help thoracic surgeons to make the right decisions in their daily practice.
\end{abstract}

Keywords: Pulmonary metastasectomy; multimodal treatment; palliative resection

Submitted Mar 11, 2020. Accepted for publication Jun 04, 2020.

doi: 10.21037/jtd-2019-pm-09

View this article at: http://dx.doi.org/10.21037/jtd-2019-pm-09

\section{Introduction}

Since many tumors involve the lung for distant spread, pulmonary metastasectomy has become an important part of the daily practice of a thoracic surgeon (1). According to the database annual report of the European Society of Thoracic Surgeons, pulmonary metastases accounted for $11.2 \%$ of all resected lung pathologies in 2019 (2). Since no randomized clinical trials exist on the topic, case selection as well as surgical practice is based on observational studies published during the last decades. However, the overall survival can be improved after pulmonary metastasectomy in carefully selected patients (1). The aim of this review article is to give an overview and to help thoracic surgeons in the treatment of patients with pulmonary metastases.

\section{Surgical approach}

There are many considerations in the discussion about the surgical approach for pulmonary metastasectomy. Minimally invasive approaches might be useful in reducing pleural adhesions and shortened postoperative recovery and can therefore be a valid choice for selected patients (3). On the other hand, small lesions might be missed since bimanual palpation of the lung it is not possible in the minimally invasive setting $(4,5)$. Therefore, in patients with multiple metastases and metastases deeply embedded within the parenchyma, thoracotomy should still be recommended to achieve complete resection (3).

The surgical approach for bilateral pulmonary metastases should also be chosen depending on number, size and 


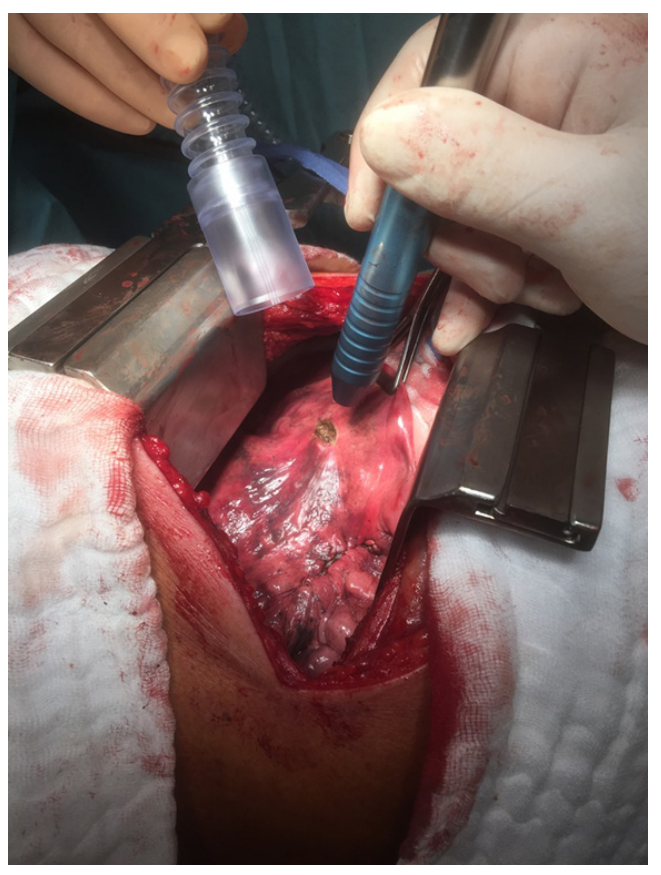

Figure 1 Pulmonary metastasectomy performed by laser via thoracotomy.

location of the metastases. One- or two-staged bilateral thoracotomy might be the most frequent approach performed in patients with multiple bilateral metastases. Two-staged surgery should be preferred in patients with limited lung function. A further advantage for staged surgery is that it allows a period of observation and provides control on a significant progression. After about 4 weeks of recovery, a re-CT should be performed followed by the second stage surgery (6). The midline sternotomy can provide access to both lungs and avoid a second surgery, but limits the access to posterior parts of the lungs. The clamshell incision has also been described as a possible approach for bilateral metastasectomy (7).

There is not much evidence on the choice of the side which is opened first, when it comes to two-staged surgery. On one hand, it can be argued that the side with the greater number of metastases or tumor mass should be opened first (6). The reason could be to find out, whether it is possible to achieve a complete resection and, if not, to avoid the unnecessary contralateral surgery. But it can also be argued that to start with the side of less tumor mass makes it possible for the patient to recover faster and to preserve more lung function for the second surgery.

The indications as well as decision about surgical approach for repeated pulmonary metastasectomy are identical to the indications for the initial operation. Furthermore, a careful preoperative evaluation of the residual lung capacity is important in patients with residual pulmonary metastases. Multimodal treatment including preoperative chemotherapy should also be discussed (8).

\section{Technical considerations}

The objective of resection of pulmonary metastases is to remove all tumor while preserving as much normal pulmonary parenchyma as possible and reduce invasiveness. Most nodules can be completely removed by wedge resection using a stapler. Metastases located in areas of the lung where a stapler cannot be applied like nearby bronchi or blood vessels can be excised by laser (Figures 1-3) (9). Wedge resection should be performed as carefully as possible to avoid local recurrence after pulmonary metastasectomy. The width of surgical margins should be decided according to the microscopic spread of satellite tumor cells. The risk of local recurrence at the surgical margins is higher after resection of metastases from colorectal cancer. Since wider safety margins can prevent local recurrence, they should be half of the diameter of the metastasis or $8 \mathrm{~mm}$ in metastases from colorectal cancer that are $12 \mathrm{~mm}$ or more $(10,11)$.

\section{Multimodal treatment options depending on selected primary tumors}

Any indication for pulmonary metastasectomy as well as systemic therapy or local measures should be discussed multidisciplinary to achieve a survival benefit for the patients. For some years now, systemic therapy includes immunotherapy and targeted therapies for some diseases. Response to immunotherapy can be prolonged, but only in approximately $20 \%$ of the patients. On the other hand, response to targeted therapies is more common, but of shorter duration (3).

Nonsurgical local treatment options for pulmonary metastases include thermal ablation techniques and stereotactic ablative body radiation (SABR). Thermal ablation techniques include microwave, cryotherapy and radiofrequency ablation (RFA). These nonsurgical treatment modalities are reasonable therapy for medically inoperable patients or high-risk for resection (3). Tumor size is an important factor when using RFA. Pulmonary metastases larger than $2-3 \mathrm{~cm}$ leads to poorer survival $(12,13)$. SABR 


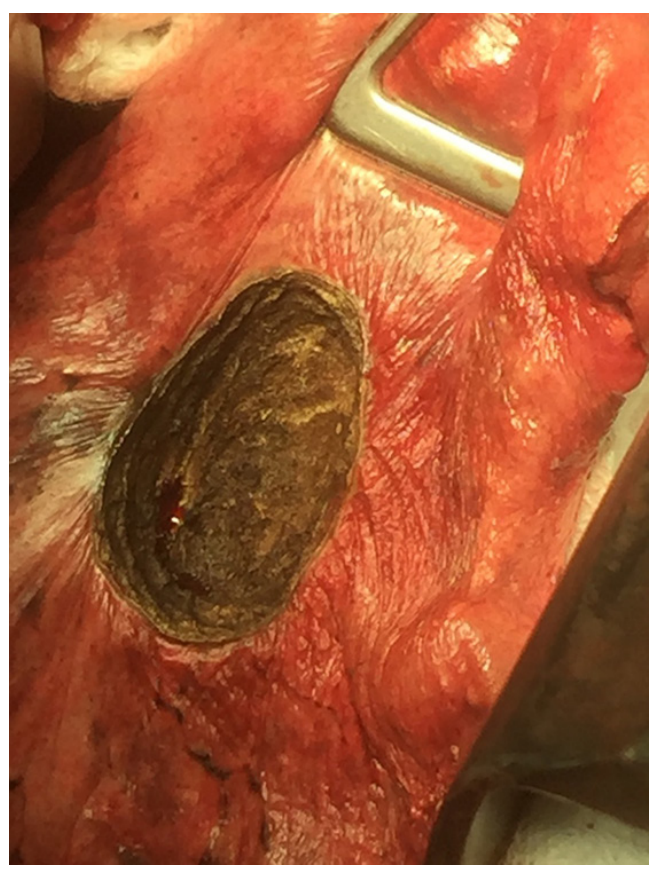

Figure 2 Airtight pulmonary cavity after laser resection.

can have an adverse impact on the lung function. On the other hand, SABR should be preferred for metastases larger than $3 \mathrm{~cm}$ in inoperable patients $(3,12)$.

\section{Colorectal carcinoma}

Since the Pulmonary Metastasectomy in Colorectal Cancer (PulMiCC) randomized controlled trial was stopped because of poor recruitment, no results from prospective controlled or randomized trials are available to confirm the benefit of pulmonary metastasectomy in patients with colorectal cancer (14). Nevertheless, 5-year survival rates up to $68 \%$ have been reported after lung metastasectomy in selected patients (15). Thus, patients with pulmonary metastases of colorectal carcinoma can be considered for pulmonary metastasectomy in combination with systemic therapy before or after surgical treatment (3). The point prevalence of intrathoracic lymph node metastases at the time of pulmonary metastasectomy can be higher in patients with rectal carcinoma, in patients with multiple pulmonary metastases and if anatomical resections had to be performed for metastasectomy (16). Lymph node metastases have an impact on survival, but even in presence of lymph node metastases a long-term survival can be

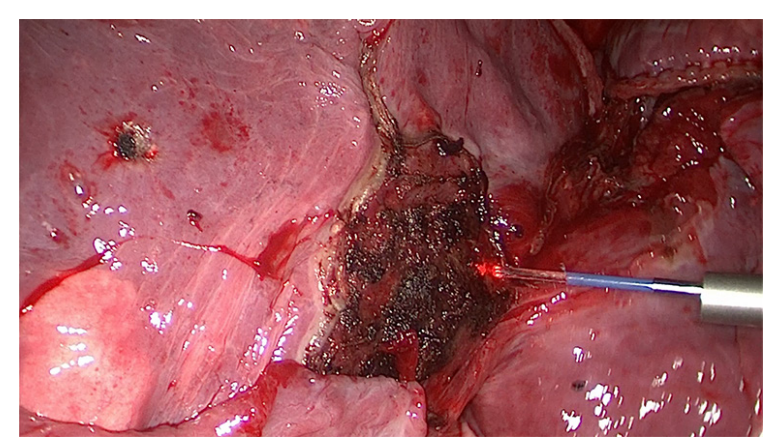

Figure 3 Pulmonary metastasectomy performed by laser via single-port videothoracoscopic approach.

reached. Therefore, it is recommended to perform a lymph node dissection or at least sampling during pulmonary metastasectomy (17-19). Finally, there is a special aspect to be noted: even in patients with pulmonary and liver metastases, complete resection can provide long-term survival in selected cases. Thus, patients with liver and pulmonary metastases should not be routinely excluded from metastasectomy $(19,20)$.

\section{Renal cell carcinoma}

Metastases of renal cell carcinoma (RCC) do not respond well to chemotherapy or radiotherapy (21). It would therefore be advisable to offer surgery to patients with potentially curative renal cell carcinoma with metastases. Consequently, resection must be as complete as possible. Intrathoracic lymph node metastases with or even without pulmonary metastases can occur in up to $47 \%$ of RCC patients. Therefore, complete resection should include a systematic lymphadenectomy to achieve a better locoregional control $(22,23)$.

\section{Germ cell tumors}

Resection of residual tumor after chemotherapy in patients with nonseminomatous germ cell tumors of testicular origin is established in the interdisciplinary concept of oncologic therapy. The serum tumor markers $\alpha$-fetoprotein, $\beta$-human chorionic gonadotropin and lactate dehydrogenase are reliable parameters for diagnosis and follow-up of the disease. Residual tumor in the lung should be removed in patients with complete serologic response after platinbased chemotherapy and residual masses of $1 \mathrm{~cm}$ or more in diameter. Other indications include lack of response 
to chemotherapy, response and then recurrence while on chemotherapy and recurrence after first line and second line platin-based chemotherapy, if applicable, including highdose chemotherapy with autologous stem cell transplant (24-27). Lymph node dissection should be performed during pulmonary metastasectomy to achieve a complete resection and because of possible different histological differentiation (17).

\section{Sarcoma}

Sarcoma is a rare tumor consisting of a heterogeneous group of histologic subtypes with a propensity to metastasize to the lungs. Since the response rate to chemotherapy is poor, pulmonary metastasectomy for sarcoma is an established treatment option in the multimodal therapy concept. Sarcoma tends to recur in the lung and can make it necessary to repeat the metastasectomy. But complete resection of pulmonary metastases can result in longterm survival in selected patients, even after repeated metastasectomies $(17,28)$. Lymph node dissection should be performed during metastasectomy of soft tissue sarcoma. Lymphadenectomy for patients with osteosarcoma is not recommended (17).

\section{Head and neck tumors}

A primary lung squamous cell carcinoma and lung metastasis of a head and neck squamous cell carcinoma are difficult to differentiate histopathologically and can lead to selection bias. Therefore, solitary lung tumors should be treated analogous to primary lung cancer. Metastases of head and neck tumors can be considered for pulmonary metastasectomy considering general suggestions for pulmonary metastases $(3,17,29)$.

\section{Breast carcinoma}

The role of pulmonary metastasectomy in patients with breast cancer remains controversial, since systemic treatment options lead to excellent long-term survival. The aim of the most pulmonary metastasectomies in breast cancer patients is to confirm the diagnosis, to exclude other primary tumor or to establish hormone receptor status. Patients with limited metastases should not generally be excluded for pulmonary metastasectomy, but only in combination with systemic hormonal, cytotoxic or targeted treatment $(3,17,30)$.

\section{Palliative treatment options}

Surgery is traditionally considered appropriate treatment for local, locoregional or oligometastatic disease, and has been primarily used curative intend treatment. Contrary, the goal of palliative pulmonary metastasectomy is to control possibly life-threatening and/or quality-of-lifeimpairing signs and symptoms, as well as to prolong life whenever possible. Possibly life-threatening situations are as follows:

(I) (Endobronchial) hemorrhage;

(II) Pneumothorax/empyema due to perforation of subpleurally located metastases;

(III) Infection/sepsis due to necrotizing metastases;

(IV) Severe pain due to tumor extension (e.g., chest wall);

(V) Severe paraneoplastic signs;

(VI) Obstruction.

Palliative treatment might be still beneficial even if metastasectomy just ameliorates clinical signs without prolonging life. Multi-disciplinary teams must weigh the risk versus benefit of metastasectomy when deciding on palliative treatment.

\section{Conclusions}

Pulmonary metastasectomies for curative intent can be carried out, if following conditions are fulfilled: local control of primary tumor, complete resections of all thoracic metastases possible, no extrathoracic metastases or can be controlled by surgery or other modalities, no alternative treatment options with lower morbidity available and adequate performance status and cardiopulmonary reserve. Minimally invasive approaches can be a valid choice for selected patients. On the other hand, in patients with multiple metastases and metastases deeply embedded within the parenchyma, thoracotomy should still be recommended to achieve complete resection.

For bilateral pulmonary metastases, the surgical approach should be chosen depending on number, size and location of the metastases. Pulmonary metastases should be removed completely while preserving as much normal pulmonary parenchyma as possible. Resection should be performed carefully with wide safety margins to avoid local recurrence. Lymphadenectomy should also be performed, whereby systematic lymph node dissection should be preferred. In case of intraoperative detection of lymph node metastases, a metastasectomy as well as lymphadenectomy 
should be performed. Palliative pulmonary metastasectomy can control possibly life-threatening situations like: hemorrhage, pneumothorax, empyema infection, sepsis, severe pain, severe paraneoplastic signs and obstruction, as well as to prolong life whenever possible. Any indication for pulmonary metastasectomy should be discussed multidisciplinary to achieve a survival benefit for the patients.

\section{Acknowledgments}

Funding: None.

\section{Footnote}

Provenance and Peer Review: This article was commissioned by the Guest Editor (Khosro Hekmat) for the series "Pulmonary Metastases" published in Fournal of Thoracic Disease. The article has undergone external peer review.

Conflicts of Interest: The authors have completed the ICMJE uniform disclosure form (available at http://dx.doi. org/10.21037/jtd-2019-pm-09). The series "Pulmonary Metastases" was commissioned by the editorial office without any funding or sponsorship. SB serves as an unpaid editorial board member of Fournal of Thoracic Disease. The authors have no other conflicts of interest to declare.

Ethical Statement: The authors are accountable for all aspects of this work in ensuring that questions related to the accuracy or integrity of any part of this work are appropriately investigated and resolved.

Open Access Statement: This is an Open Access article distributed in accordance with the Creative Commons Attribution-NonCommercial-NoDerivs 4.0 International License (CC BY-NC-ND 4.0), which permits the noncommercial replication and distribution of the article with the strict proviso that no changes or edits are made and the original work is properly cited (including links to both the formal publication through the relevant DOI and the license). See: https://creativecommons.org/licenses/by-nc-nd/4.0/.

\section{References}

1. Pastorino U, Buyse M, Friedel G, et al. Long-term results of lung metastasectomy: prognostic analyses based on 5206 cases. J Thorac Cardiovasc Surg 1997;113:37-49.
2. Database Annual Report 2019. The European Society of Thoracic Surgeons. [cited 2020 Jan 08]. Available online: http://www.ests.org/_userfiles/pages/files/database_ reports/ESTS\%202019\%20Silver\%20Book.pdf.

3. Handy JR, Bremner RM, Crocenzi TS, et al. Expert Consensus Document on Pulmonary Metastasectomy. Ann Thorac Surg 2019;107:631-49.

4. Chen H, Huang S, Zeng Q, et al. A retrospective study analyzing missed diagnosis of lung metastases at their early stages on computed tomography. J Thorac Dis 2019;11:3360-8.

5. Eckardt J, Licht PB. Thoracoscopic or open surgery for pulmonarymetastasectomy: an observer blinded study. Ann Thorac Surg 2014;98:466-9.

6. Molnar TF, Gebitekin C, Turna A. What are the considerations in the surgical approach in pulmonary metastasectomy? J Thorac Oncol 2010;5:S140-4.

7. Downey RJ, Bains MS. Open Surgical Approaches for Pulmonary Metastasectomy. Thorac Surg Clin 2016;26:13-8.

8. Park JS, Kim HK, Choi YS, et al. Outcomes after repeated resection for recurrent pulmonary metastases from colorectal cancer. Ann Oncol 2010;21:1285-9.

9. Rusch VW. Pulmonary metastasectomy. Current indications. Chest 1995; 107:322S-331S.

10. Shiono S, Ishii G, Nagai K, et al. Predictive factors for local recurrence of resected colorectal lung metastases. Ann Thorac Surg 2005;80:1040-5.

11. Welter S, Barile La Raia R, Gupta V. Pursuit of an optimal surgical margin in pulmonary metastasectomy. J Vis Surg 2019;5:39.

12. Simon CJ, Dupuy DE, DiPetrillo TA, et al. Pulmonary radiofrequency ablation: long-term safety and efficacy in 153 patients. Radiology 2007;243:268-75.

13. de Baère T, Auperin A, Deschamps F, et al. Radiofrequency ablation is a valid treatment option for lung metastasectomytases: experience in 566 patients with 1037 metastasectomytases. Ann Oncol 2015;26:987-91.

14. Treasure T, Farewell V, Macbeth F, et al. Pulmonary Metastasectomy versus Continued Active Monitoring in Colorectal Cancer (PulMiCC): a multicenter randomised clinical trial. Trials 2019;20:718.

15. Okumura T, Boku N, Hishida T, et al. Surgical outcome and prognostic stratification from pulmonary metastasis from colorectal cancer. Ann Thorac Surg 2017;104:979-87.

16. Bölükbas S, Sponholz S, Kudelin N, et al. The Prevalence of Lymph Node Metastases and Factors affecting Longterm survival after Pulmonary Metastasectomy for 
Colorectal Cancer. Ann Thorac Surg 2014;97:1926-32.

17. Bölükbas S, Pfannschmidt J, Krüger M, et al. Lymphadenectomy during Potentially Curative Pulmonary Metastasectomy-Recommendations of an Expert Consensus Panel using the Delphi Process. Zentralbl Chir 2020;145:288-92.

18. Welter S, Jacobs J, Krbek T, et al. Prognostic impact of lymph node involvement in pulmonary metastases from colorectal cancer. Eur J Cardiothorac Surg 2007;31:167-72.

19. Pfannschmidt J, Dienemann H, Hoffmann H. Surgical resection of pulmonary metastases from colorectal cancer: a systematic review of published series. Ann Thorac Surg 2007;84:324-38.

20. Sponholz S, Bölükbas S, Schirren M, et al. Liver and lung metastases of colorectal cancer. Long-term survival and prognostic factors. Chirurg 2016;87:151-6.

21. Motzer RJ, Bander NH, Nanus DM. Renal-cell carcinoma. N Engl J Med 1996;335:865-75.

22. Renaud S, Falcoz PE, Olland A, et al. Should mediastinal lymphadenectomy be performed during lung metastasectomy of renal cell carcinoma? Interact Cardiovasc Thorac Surg 2013;16:525-8.

23. Kudelin N, Bölükbas S, Eberlein M, et al. Metastasectomy with Standardized LymphNode Dissection for Metastatic Renal Cell Carcinoma: An 11-year Single Center Experience. Ann Thorac Surg 2013;96:265-70.

Cite this article as: Baldes N, Eberlein M, Bölükbas S. Multimodal and palliative treatment of patients with pulmonary metastases. J Thorac Dis 2021;13(4):2686-2691. doi: 10.21037/jtd2019-pm-09
24. Pfannschmidt J, Hoffmann H, Dienemann H. Thoracic metastasectomy for nonseminomatous germ cell tumors. J Thorac Oncol 2010;5:S182-6.

25. Liu D, Abolhoda A, Burt ME, et al. Pulmonary metastasectomy for testicular germ cell tumors: a 28-year experience. Ann Thorac Surg 1998;66:1709-14.

26. Schirren J, Trainer S, Eberlein M, et al. The role of residual tumor resection in the management of nonseminomatous germ cell cancer of testicular origin. Thorac Cardiovasc Surg 2012;60:405-12.

27. Einhorn LH, Williams SD, Chamness A, et al. High dose chemotherapy and stem cell rescue for metastatic germ cell tumors. N Engl J Med 2007;357:340-8.

28. Pfannschmidt J, Klode J, Muley T, et al. Pulmonary metastasectomy in patients with soft tissue sarcomas: Experiences in 50 patients. Thorac Cardiovasc Surg 2006;54:489-92.

29. Winter H, Meimarakis G, Hoffmann G, et al. Does surgical resection of pulmonary metastases of head and neck cancer improve survival? Ann Surg Oncol 2008;15:2915-26.

30. Fan J, Chen D, Du H, et al. Prognostic factors for resection of isolated pulmonary metastases in breast cancer patients: a systematic review and meta-analysis. J Thorac Dis 2015;7:1441-51. 